\title{
Poison's legacy
}

Previously published at www.cmaj.ca

The Poisoner's Handbook: Murder and the
Birth of Forensic Medicine in Jazz Age
New York
Deborah Blum
Penguin Group (USA); 2010 .

$\mathrm{S}$ itting back and watching the exploits of the fictional crime scene investigation teams of Miami, Las Vegas and New York on television, one might be forgiven for assuming that unravelling murder mysteries is no big deal. All you need to do, it seems, is to insert a scraping of the victim's blood into a sophisticated machine and wait 15 seconds for a report that not only identifies the lethal compounds that caused her tragic demise, but can also describe what she ate for breakfast three weeks earlier, if so desired.

It is, of course, nowhere nearly as simple as that, as any real life investigator can attest to, though there have been significant advances made in forensic medicine since toxicology first came into being in the second decade of the 20th century. This book documents the beginning of that journey.

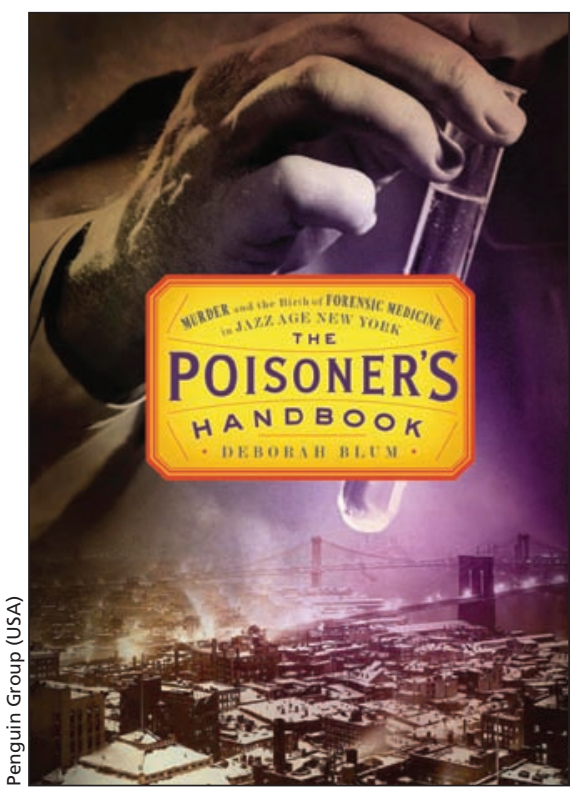

toil to extract and identify their presence with methods later used on human flesh when poisoning was suspected.

In The Poisoner's Handbook, the toxins in question, such as arsenic and cyanide, and the tales of how they were delivered to the victims often sound like something straight out of Agatha Christie. Consider for example, the case of the woman who decided to dispatch her newly acquired six-year-old stepson

\section{"The government knows it is not stopping drinking by putting poison in alcohol."}

In 1918, Dr. Charles Norris was named Chief Medical Examiner of New York City, succeeding a long string of often incompetent political appointees, one of whom was notorious for arriving at crime scenes too drunk to stand without support. One of Norris' first hires was a chemist named Alexander Gittler, who was passionate about developing new ways of teasing out and identifying $\vec{\infty}$ the toxins responsible for the deaths of the newly departed who were arriving at the coroner's office on a daily basis. Using chunks of liver purchased from a local butcher, various reagents, stills and a microscope, Gittler would inject various substances into the meat and then by sending him a box of cyanide-laced chocolates while he was out of state visiting his aunt.

Much more common, however, during that era of Prohibition (1920-1933) were self-induced methanol poisonings, as consumers threw caution to the wind and imbibed whatever they could find. Often leaving its victims permanently blind - when not killing them outright - methanol was cheaper and much easier to come by than the more tightly regulated ethanol, and was mixed into much of what unscrupulous bootleggers were smuggling into the speakeasies of New York. But as author Deborah Blum points out, the bootleggers were but partly to blame. In 1926, the federal government, in an effort to enforce the socalled "Noble Experiment," mandated adding poisons (including methanol) to industrial alcohol so as to discourage people from drinking it. Unfortunately, instead of leading to decreased consumption, this only resulted in more death and suffering, with the toll from that year's Christmas celebrations reaching 23 dead and dozens more blinded in New York City alone.

Distraught at the horror he was witnessing, Norris issued a public statement on Dec. 28, 1926, stating that "the government knows it is not stopping drinking by putting poison in alcohol. It knows what the bootleggers are doing with it and yet it continues its poisoning process, heedless of the fact that people determined to drink are daily absorbing that poison. Knowing this to be true, the United States Government must be charged with the moral responsibility for the deaths that poisoned liquor causes." Despite public outcry and the rising death toll from poisoned alcohol (which Blum has elsewhere estimated to be approximately 10000 ) this policy continued until Prohibition was repealed seven years later.

Each chapter of this beautifully written book is devoted to a specific poison, through which, in a manner evocative of Primo Levi's The Periodic Table, the author tells the stories of Norris and Gittler and the cases they solved. She also successfully conveys the atmosphere of the period, and how society then grappled with issues such as substance abuse and abortion that we continue to struggle with today. This is no less a biography and a history of the establishment of forensic science as a discipline than a literary work of social commentary, and is extremely thoughtprovoking and enjoyable.

\section{Dennis Rosen MD \\ Division of Respiratory Diseases \\ Children's Hospital Boston \\ Harvard Medical School \\ Boston, USA}

